\title{
A cantilever approach to estimate bending stiffness of buildings affected by tunnelling
}

\author{
Twana Kamal Haji ${ }^{a, *}$, Alec M. Marshall ${ }^{a}$, Walid Tizani ${ }^{a}$ \\ ${ }^{a}$ Department of Civil Engineering, Faculty of Engineering, University of Nottingham, \\ Nottingham, United Kingdom.
}

\begin{abstract}
The evaluation of the effect of tunnel construction on buildings is a problem being faced by engineers around the world. Building bending stiffness is an important parameter in tunnel-soil-structure interaction analyses. The construction of a new tunnel influences an existing building via induced ground movements, and the existence of a building also affects ground displacements due to tunnelling via its stiffness and weight. The magnitude of the effect depends on the properties of the building and foundation as well as the complex soil-structure interactions that occur. In this paper, an approach is proposed in which the building response to tunnelling is related to the bending of a cantilever beam and empirical-type relationships are developed to predict building bending stiffness. This approach is relevant to cases where the building is perpendicular to the tunnel axis and its nearest edge does not overlap more than half of the tunnel cross-section. Rigorous finite element analyses are used to evaluate the response of buildings to ground displacements and expressions are provided which relate three-dimensional building bend-
\end{abstract}

\footnotetext{
*Corresponding author

Email address: twana.k.haji@gmail.com (Twana Kamal Haji )
}

Preprint submitted to Tunnelling and Underground Space Technology August 3, 2017 
ing stiffness to a simple beam theory expression. The results show that lower storeys have a proportionally higher stiffness effect than higher storeys. In addition, the parameters that affect the global behaviour of the building, such as component stiffness and geometry, are studied. The suggested approach provides a relatively quick and easy way of accurately evaluating building bending stiffness for use within tunnel-soil-structure interaction analyses.

Keywords: Soil-structure interaction, Tunnel, Building, Bending stiffness, Cantilever behaviour 


\section{List of Notations}

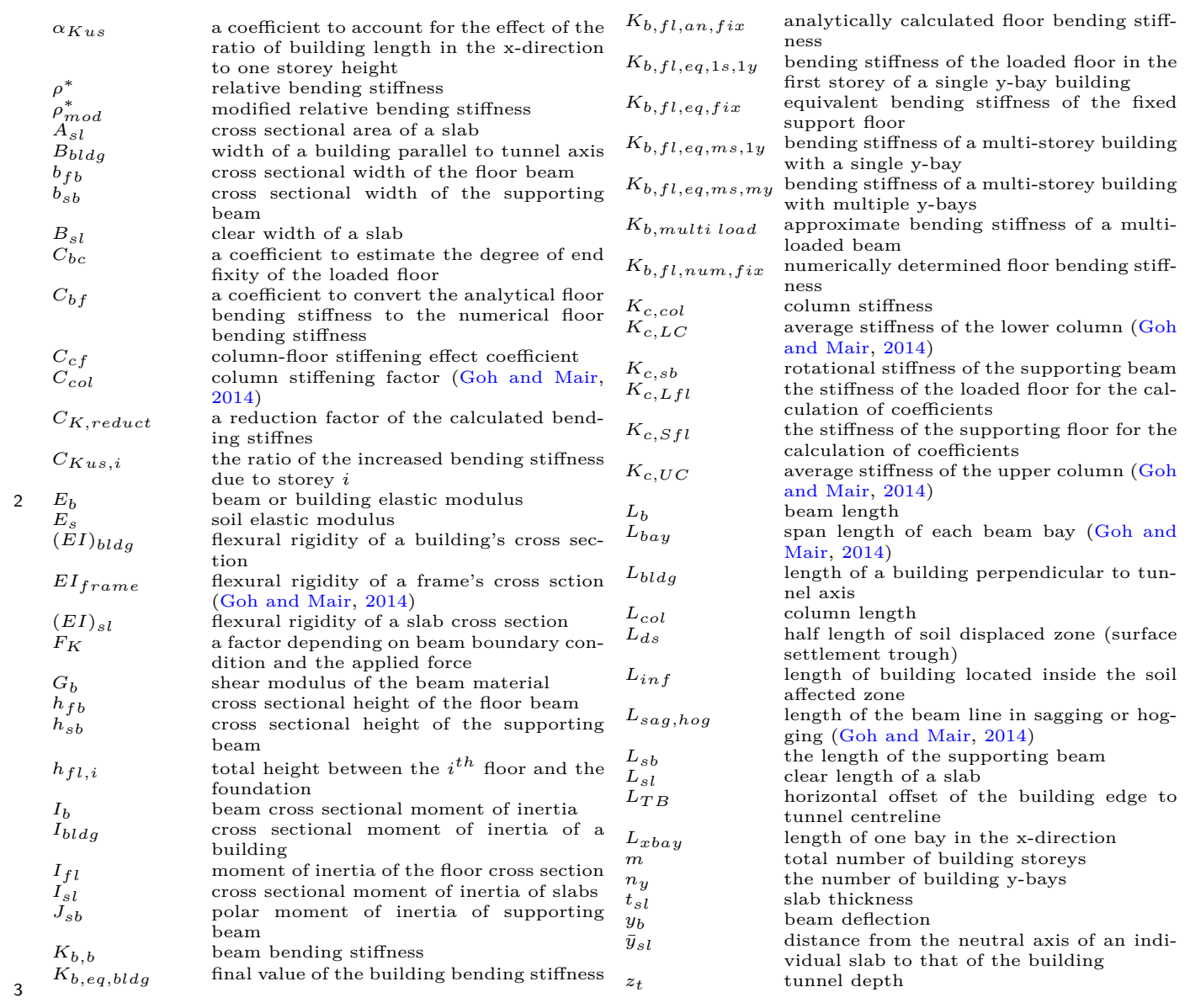

\section{1. Introduction}

5 The popularity of tunnel construction within urban areas for provision

6 of transport and other essential infrastructure is increasing. Tunnel con-

7 struction inevitability causes ground movements which can have detrimental

8 effects on nearby structures and buried infrastructure. The analysis of tun-

9 nelling induced displacements and tunnel-structure interaction has received

10 considerable attention by the research community (e.g. Mair and Taylor 
(1997); Mair (2013)). The focus of this paper relates to the effect of tunnelling on buildings. Research in this area has included field investigations (Boscardin and Cording, 1989; Dimmock and Mair, 2008; Farrell et al., 2014), experimental studies, including geotechnical centrifuge tests at elevated gravity (Farrell and Mair, 2012; Giardina et al., 2012; Farrell et al., 2014), numerical analyses (Potts and Addenbrooke, 1997; Mroueh and Shahrour, 2003; Franzius et al., 2006; Pickhaver et al., 2010; Maleki et al., 2011; Mirhabibi and Soroush, 2013; Fargnoli et al., 2015), and the development of analysis methods for evaluating building deformations (Rankin, 1988; Attewell et al., 1986; Franza et al., 2017).

The level of complexity of the tunnel-building interaction analyses varies considerably. In the simplest form, it is assumed that the building deforms according to greenfield displacements (Rankin, 1988). However, in reality the building influences the resulting soil movements due to its stiffness (Potts and Addenbrooke, 1997; Mair and Taylor, 1997) and weight (Liu et al., 2001; Mroueh and Shahrour, 2003; Franzius et al., 2004; Giardina et al., 2015).

This paper deals specifically with how building stiffness can be evaluated; this stiffness value can then be used to inform analyses of tunnel-building interaction. Several researchers have investigated the effect of structural stiffness on tunnelling- or excavation-induced ground movements, such as Potts and Addenbrooke (1997); Franzius et al. (2006); Dimmock and Mair (2008); Goh and Mair (2014); Giardina et al. (2015); Franza et al. (2017). The methods used to estimate the stiffness of the building vary. Lambe (1973) algebraically added the individual flexural rigidity of all floor slabs, $(E I)_{s l}$, to calculate the whole building stiffness: $(E I)_{b l d g}=\sum(E I)_{s l}$, where $E$ is the 
material modulus of elasticity and $I$ is the cross sectional moment of inertia; subscripts bldg and sl denote building and slab, respectively. Potts and Addenbrooke (1997) proposed Equation 1 to estimate the bending stiffness of a building relative to the soil.

$$
\rho^{*}=\frac{(E I)_{b l d g}}{E_{s}\left(\frac{L_{b l d g}}{2}\right)^{4}}
$$

where $\rho^{*}$ is the relative bending stiffness, $E_{s}$ is the soil elastic modulus, and $L_{b l d g}$ is the building length in the direction perpendicular to the tunnel axis. The building was represented by an equivalent beam in their analysis. The expression $(E I)_{b l d g} /\left(L_{b l d g} / 2\right)^{4}$ of Equation 1 represents the bending stiffness of the building. The parallel axis theorem was used to evaluate the building moment of inertia, $I_{b l d g}$, for a building of $m$ storeys with $m+1$ slabs: $I_{b l d g}=\sum_{i=1}^{m+1}\left(I_{s l, i}+A_{s l, i} \cdot \bar{y}_{s l, i}^{2}\right)$, where $A_{s l}$ is the cross sectional area of a slab and $\bar{y}_{s l, i}$ is the distance from the neutral axis of the $i^{\text {th }}$ slab to the neutral axis of the building. Potts and Addenbrooke (1997) also proposed the popular modification factor approach in which parameters used to evaluate building damage are compared based on displacements when soil-structure interaction is either considered or ignored (the greenfield condition).

Franzius et al. (2006) extended the work of Potts and Addenbrooke (1997) by considering the building width and the tunnel depth, as shown in Equation 2 .

$$
\rho_{\text {mod }}^{*}=\frac{(E I)_{b l d g}}{E_{s} z_{t} B_{b l d g} L_{b l d g}^{2}}
$$

where $\rho_{m o d}^{*}$ is the modified relative bending stiffness, $B_{b l d g}$ is the building width parallel to the tunnel axis, and $z_{t}$ is the tunnel depth. The expression 
${ }_{41}(E I)_{b l d g} /\left(B_{b l d g} L_{b l d g}^{2}\right)$ represents the bending stiffness of the building in this 42 case.

Goh and Mair (2014) used the column stiffening factor $\left(C_{c o l}\right)$ proposed by Meyerhof (1953) to increase the flexural rigidity of an entire beam line in a rigidly connected frame:

$$
C_{c o l}=1+\frac{L_{\text {sag }, h o g}^{2}}{L_{b a y}^{2}}\left(\frac{K_{c, L C}+K_{c, U C}}{K_{c, L C}+K_{c, U C}+K_{c, b}}\right)
$$

where $L_{\text {sag,hog }}$ is the length of the beam line in sagging or hogging, $L_{b a y}$ is the span length of each beam bay, $K_{c, L C}$ and $K_{c, U C}$ are the average stiffness $\left(=(E I)_{c o l} / L_{c o l}\right)$ of the lower $(L C)$ and upper $(U C)$ columns, respectively, $L_{c o l}$ is the column height, and $K_{c, b}=(E I)_{b} / L_{b a y}$ is the average stiffness of the beam line. The bending stiffness of the frame is then estimated by $E I_{\text {frame }}=\sum\left((E I)_{b} * C_{\text {col }}\right)_{i^{\text {th }} \text { floor }}$ The accurate evaluation of building bending stiffness in tunnel-building interaction analyses is clearly important. However, the real behaviour of three-dimensional (3D) buildings in response to applied displacements from the ground is disregarded to a great extent. Results from the literature relating to numerical analyses of 3D buildings provide a good general appreciation of tunnelling effects on buildings, but a detailed understanding of how structural elements contribute to the stiffness of the entire building system is still missing. Furthermore, the available methods for building stiffness estimation are mainly based on representing the building as a $2 \mathrm{D}$ beam or frame and assuming it acts as a single entity, disregarding the effect of the stiffness contribution of each storey to the global building stiffness. The purpose of this 
paper is to propose a new method for accurately estimating the true bending stiffness of 3D concrete framed buildings subjected to tunnelling induced ground movements. The method is based on results obtained from rigorous finite element (FE) analyses that are able to replicate the real behaviour of structures. Note that bending stiffness of a building in this paper is defined as the ratio of the applied load to the resulting displacement of the building.

\section{Methodology}

In this work, the building is treated as an independent entity with respect to the soil and the foundation; the method solely focuses on determining the bending stiffness of the building superstructure. A view of the building, including various geometric parameters, is shown in Figure 1a. The analysis considers the interaction between a newly constructed tunnel and an existing building that runs perpendicular to the tunnel. In addition, the method applies to the case where the plan area of the building does not cover more than half of the cross-section of the tunnel (Figure 1b). In this scenario, an analogy may be made between the induced deformation of the building and that of a cantilever beam loaded at its end, as illustrated in Figure 1c. This analogy is fundamental to the proposed approach as it allows relationships to be developed which relate accurate assessments of building deformation obtained from FE analyses to those of a simple analytical expression for bending of a cantilever beam. The cantilever-beam analogy is chosen because, in the case where the tunnel is not located directly under the building, the deformed shape of the building does not include a sagging zone and coincides well with the hogging shape of a cantilever beam loaded at its end. 


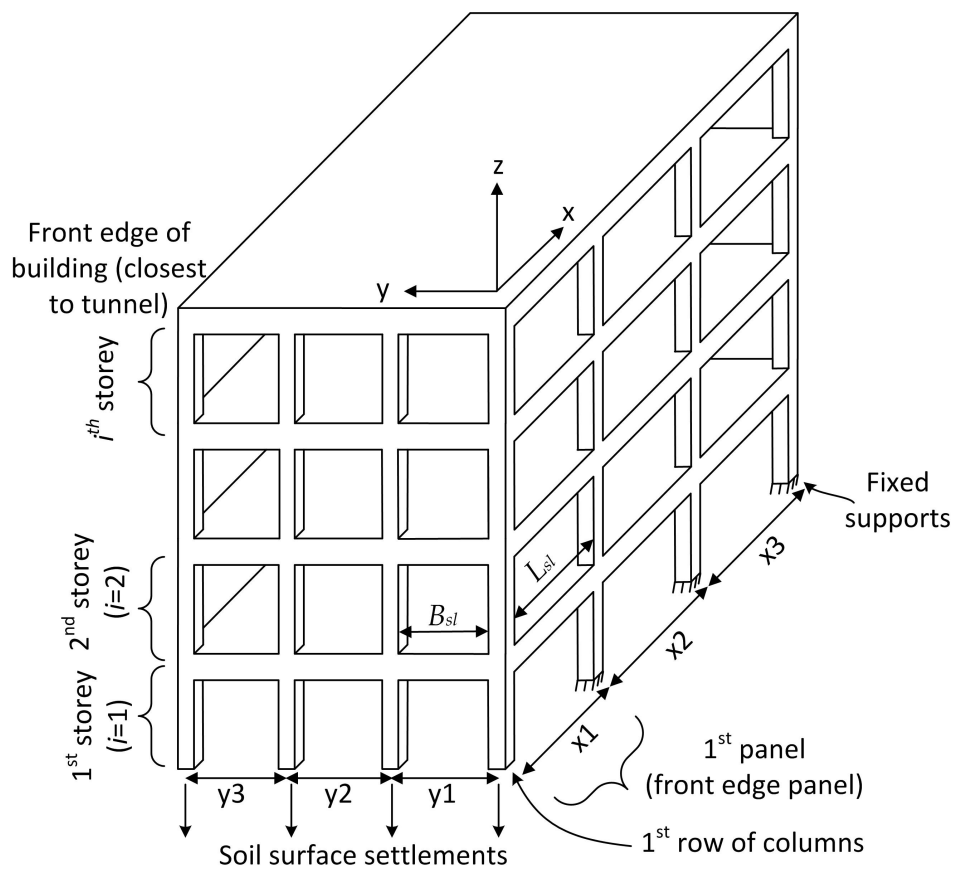

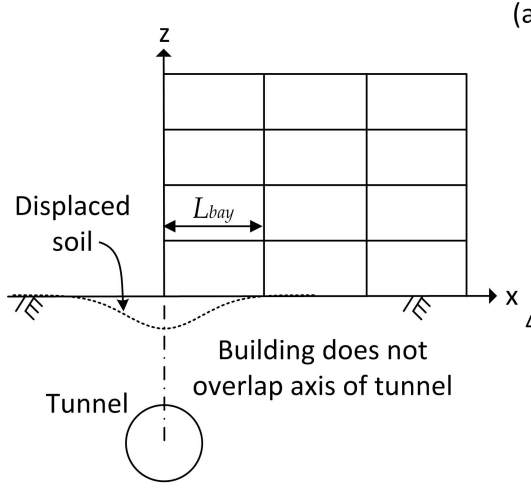

(b) (a)

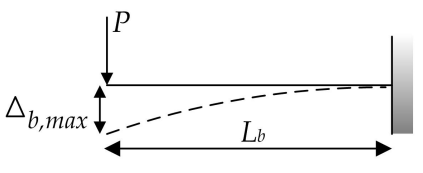

(c)

Figure 1: (a) Isometric view of framed building, (b) 2D view of building and tunnel, and (c) cantilever beam 
In the paper, a panel refers to the combination of a slab, four beams and four columns with a length perpendicular and a width parallel to the tunnel centreline. The slab of each panel has a clear width of $B_{s l}$ and a clear length of $L_{s l}$. The maximum size of the slabs considered was $7 \times 8 \mathrm{~m}$ $\left(B_{s l} \times L_{s l}\right)$ due to the need for a very fine mesh to achieve accurate numerical results (based on comparison to analytical solutions). This maximum slab size represents a common panel size in buildings. Each storey consists of a group of panels at the same level; the ground-floor is referred to as the $1^{\text {st }}$ storey (Figure 1a). An individual floor in a panel is made up of a slab and two beams in the direction perpendicular to the tunnel (x-axis in Figure 1). The slab and beams in a floor are considered as a single entity, rather than separate structural elements, as shown in Figure 3a.

Mathematically, bending stiffness of a beam loaded with a force can be derived from the expression for deflection (Equation 4). The essential parameters on which bending stiffness of a beam depend are the material elastic modulus, $E_{b}$, cross sectional moment of inertia, $I_{b}$, and the moment applied to the beam, $M_{b}$, which depends on the applied force, $P$, beam length, $L_{b}$, and the boundary condition. The analytical equation of beam bending stiffness can be expressed by Equation 5 .

$$
\begin{array}{r}
\frac{d^{2} y_{b}}{d x^{2}}=\frac{M_{b}(x)}{(E I)_{b}} \\
K_{b, b}=F_{K} \times \frac{(E I)_{b}}{L_{b}^{3}}
\end{array}
$$

where $y_{b}$ is the deflection, $x$ is distance along the beam, $d^{2} y_{b} / d x^{2}$ is the curvature, $M_{b}(x)$ is the moment at any point along the beam, $K_{b, b}$ is the bending 
stiffness, and $F_{K}$ is a factor depending on the boundary condition of the beam and the applied force. This form of equation is based on concentrated forces, $P$, or equivalent total forces for cases of distributed loads. Note that Equation 5 relates to the case where maximum deflection along the beam is considered. The term $K_{b}$ is used in this paper to denote bending stiffness.

The methodology considers the contribution of the various structural parts to the overall stiffness of the building using five stages, as illustrated in Figure 2. Stage 1 compares the behaviour of a single floor in an edge panel (Figure 3a) to that of a cantilever beam fixed at one end and loaded at the other (Figure 1c). Stage 2 considers the effect of the actual boundary condition of the cantilever floor (which was assumed to be fixed in stage 1) by adding more bays in the $\mathrm{x}$-direction (Figure 3c). This step determines the value of $F_{K}$ in Equation 5. Stage 3 determines the effect of adding storeys (Figure 3d), while Stage 4 considers the effect of adding bays in the y-direction. In stages 1 to 4 , the assumption is made that only the first panel (x-bay) of the building is affected by soil displacements; Stage 5 considers the case where multiple x-bays are affected (i.e. wider settlement trough).

In the analysis, the following assumptions were made. [i] The building material is concrete and the behaviour of all structural members is elastic. [ii] The building is weightless. [iii] All joints in the building are rigidly connected (no rotation). [iv] The width of the column cross section (parallel to the tunnel axis) coincides with the width of the floor beam $\left(b_{c o l}=b_{f b}\right)$, and its cross sectional height (perpendicular to the tunnel axis) coincides with the width of the supporting beam $\left(h_{c o l}=b_{s b}\right)$ (Figure 3a). [v] The bay length does not vary along the building length in each direction (e.g. all bays in x- 


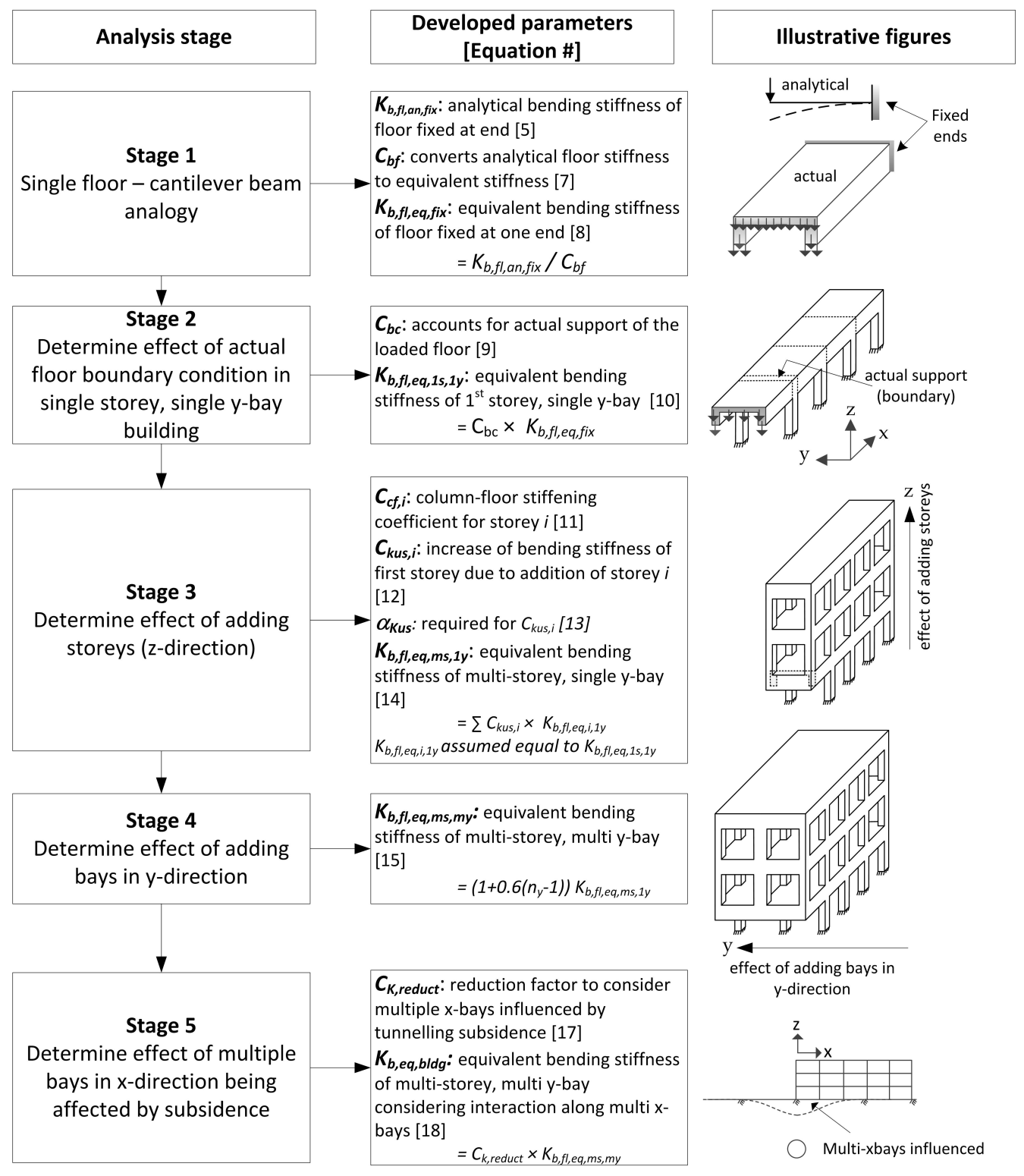

Figure 2: Flow chart of the stages of analysis 
direction are of the same length, but not necessarily the same length as in the y-direction). Furthermore, all storeys are the same in terms of dimensions and material properties. [vi] The stiffness of the loaded beam (Figure 3b,c) has no effect on the bending stiffness of the floor, and the stiffness of all partition walls (bearing and non-bearing) has no effect on the building bending stiffness. [vii] Tunnelling induced ground displacements are transferred through columns to the loaded beam, which are then distributed uniformly over the floor cross section (the slab and two floor beams), Figure 3a,b. The ABAQUS finite element software (SIMULIA, 2012) was used for the numerical analyses. All parts were created using 3D 8-node linear brick, reduced integration solid elements (C3D8R).

\section{Stage 1: cantilever beam analysis of single floor}

If only the row of edge columns (Figure 1a) is subjected to downwards displacement then edge floors will act as cantilever beams (Figure 1c). Equation 5 can be used for calculating the maximum deflection of a cantilever beam using $F_{K}=3$. Numerical simulations in this stage investigate how floors behave when they are fixed at one end and loaded at the other in order to make a direct comparison with analytical results achieved using Equation 5. Note that Figure 3 gives an illustration of the numerical models used for the analyses in this and subsequent sections.

An edge floor can be represented by a cantilever beam if the transferred forces or displacements are distributed uniformly over its cross section, as shaded in Figure 3c (based on the previously stated assumption [vii]). For this case, the moment of inertia of the floor cross section $\left(I_{f l}\right)$ may be used 



Figure 3: (a) Typical floor subjected to displacements, (b) conveying displacement effects through columns to beams, (c) typical numerical model of a single storey, single y-bay building, (d) single y-bay, multi x-bay and multi storey building 
in Equation 5. $I_{f l}$ includes the moment of inertia of both floor beams and the slab as one rigid body, and is calculated using the parallel axis theorem. Numerical simulations were conducted to consider a range of sizes of the structural parts, as shown in Table 1 , where $t_{s l}$ is the slab thickness, $b_{f b}, b_{s b}$ are the cross sectional widths of the floor and supporting beams, respectively, and $h_{f b}, h_{s b}$ are the cross sectional heights of the floor and supporting beams, respectively.

Table 1: Range of sizes of structural parts considered in stage 1 analyses

\begin{tabular}{|l|c|c|c|c|c|}
\hline Parameter & $L_{s l}$ & $B_{s l}$ & $t_{s l}$ & $b_{f b}$ and $b_{s b}$ & $h_{f b}$ and $h_{s b}$ \\
\hline Range $(\mathrm{m})$ & 1 to 8 & 1 to 7 & 0.075 to 0.2 & 0.2 to 0.6 & 0.2 to 0.75 \\
\hline
\end{tabular}

In this stage, the supporting beam shown in Figure 3c was not modelled. Instead, a fixed boundary was applied to that end of the floor (at the end of length $L_{f l}$, excluding $b_{s b}$ ). The applied distributed displacements to the floor cross section are also shown in Figure 3a. The sum of the nodal reaction forces were determined and divided by the applied displacement to obtain the numerically determined (subscript num) floor bending stiffness $\left(K_{b, f l, n u m, f i x}\right)$ for a fixed support (subscript $f i x)$ :

$$
K_{b, f l, \text { num }, \text { fix }}=\frac{\sum P_{\text {nodes }}}{\Delta_{\text {applied }}}(N / m)
$$

where $\sum P_{\text {nodes }}$ is the sum of the nodal reaction forces created by the applied displacements, and $\Delta_{\text {applied }}$ is the applied displacement.

Figure 4a shows the ratio of floor bending stiffness calculated using Equation $5\left(K_{b, f l, a n, f i x}\right)$, where subscript an indicates an analytically determined value, to that determined from the numerical analysis $\left(K_{b, f l, n u m, f i x}\right)$ at dif- 
ferent values of $L_{s l} / B_{s l}$. In one set of simulations, the slab width $\left(B_{s l}\right)$ and beam cross sections were constant and only the length of the slab $\left(L_{s l}\right)$ was changed (variable $L_{s l}$ ). In the other set, $L_{s l}$ and beam cross sections were constant and $B_{s l}$ was varied (variable $B_{s l}$ ). Figure 4 a demonstrates that the deflection of the edge floors subjected to displacements along their exterior edge is very close to that of a cantilever beam when $L_{s l} / B_{s l}>1.25$ (difference of less than 10\%). Therefore, Equation 5 can be used directly to compute its bending stiffness when $L_{s l} / B_{s l}>1.25$.



(a)

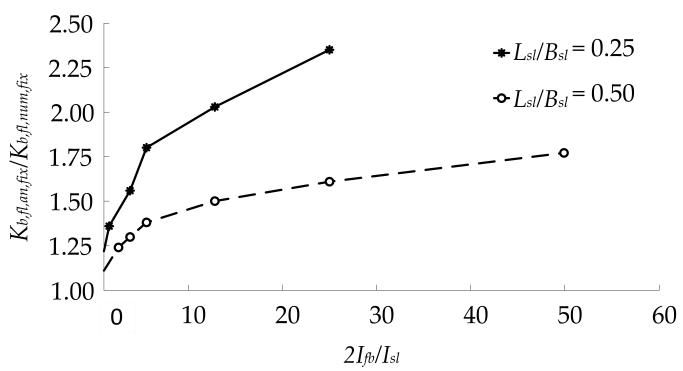

(b)

Figure 4: (a) Ratio of analytical to numerical floor bending stiffness for different $L_{s l} / B_{s l}$ values, (b) effect of $2 I_{f b} / I_{s l}$ on floor bending stiffness

The reason for the slight overestimation of the floor bending stiffness for $L_{s l} / B_{s l}>1.25$ when using Equation 5 is related to the difference in the bending stiffness of the individual slab and beams in the floor system. In a monolithically cast beam-slab system, the interior and edge beam cross sections will be T- or L-shaped, as shown in Figure 5a (e.g. see McCormac and Brown, 2014; Wight and MacGregor, 2009). When $B_{s l}$ is small compared to $L_{s l}$, a significant part of the slab acts as a beam $\left(b_{e f f}\right.$, as illustrated in Figure 5a), which produces a beam behaviour in the global floor. The size of $b_{e f f}$ depends on $L_{s l}$. Furthermore, when $L_{s l}$ is large, both floor members (the 
beams and the slab) are sufficiently flexible to deform together when they are affected by a load. Therefore, when the beam behaviour is dominant in the floor system, the floor bending stiffness can be calculated reasonably well using Equation 5.

For $L_{s l} / B_{s l} \leq 1.25$ (i.e. small $L_{s l}$ or larger $B_{s l}$ ), a smaller portion of the slab will act as a beam (small $b_{e f f}$ ) and the remaining portion of the slab will be of considerable size in the floor system. In such cases, the bending stiffness of individual beams becomes considerably larger than that of the slab due to having a larger cross sectional height (greater moment of inertia). For this reason, the force required to displace the slab by a specific amount will be smaller than for the beams. This means that, regardless of how a uniform displacement is applied to the cross section of the floor in the numerical analysis, the corresponding forces will not be uniform over the floor crosssection; the slab will have smaller forces than the beams. In Equation 5, the slab and beams in the floor system are assumed to show the same stiffness and deflect by the same amount. Therefore, the summation of $P_{\text {nodes }}$ in the numerical analysis leads to a lower value of bending stiffness of the floor system compared to that calculated using Equation 5.

The ratio of the bending stiffness of floor beams $\left(2 K_{b, f b}\right)$ to that of the slab $\left(K_{b, s l}\right)$ in the floor system also has a considerable effect on the stiffness overestimation of floors with small lengths $\left(L_{s l}\right)$. Simulations were conducted in which the length and the elastic modulus of the beams and slabs were kept the same. Therefore, the ratio of bending stiffness of beams to that of the slab can be taken as the ratio of the moments of inertia: $2 I_{f b} / I_{s l}$, as plotted in Figure $4 \mathrm{~b}$ for two specific cases of $L_{s l} / B_{s l}$. 


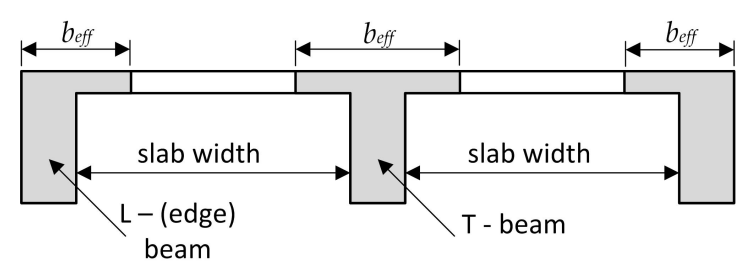

(a)

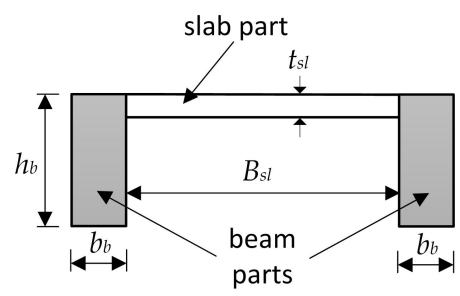

(b)

Figure 5: (a) Effective beam width $\left(b_{e f f}\right)$ in edge or interior beams, (b) beam and slab parts for the calculation of the moment of inertia of floor cross section

Based on the numerical results of varying $L_{s l}, B_{s l}$ and $2 I_{f b} / I_{s l}$, a coefficient $C_{b f}$ (Equation 7) can be used to modify the analytical floor bending stiffness calculated by Equation 5 to reasonably match the numerical model results of the bending stiffness of a cantilever floor when $L_{s l} / B_{s l} \leq 1.25$. This coefficient takes into account the effects of the moment of inertia of the slab and floor beams, and is approximately equal to $K_{b, f l, a n, f i x} / K_{b, f l, n u m, f i x}$.

$$
C_{b f}=\left(\frac{6 I_{f b}}{I_{s l}}\right)^{\frac{B_{s l}}{20 L_{s l}}} \geq 1.0
$$

where values of $I_{f b}$ and $I_{s l}$ are calculated independently of each other according to the cross-sectional areas shown in Figure 5b. The main factor causing the differences between numerical and analytical results is the bending stiffness of the beams, which is largely affected by $L_{s l}$. For this reason, in the expression of $C_{b f}$, the term $\left(2 I_{f b} / I_{s l}\right)$ is factored by 3 and $L_{s l}$ by 20 . Figure 6 illustrates the good fit obtained by using $C_{b f}$ (i.e. a good match with $\left.K_{b, f l, a n, f i x} / K_{b, f l, n u m, f i x}\right)$.

To summarise, the analytically computed bending stiffness of the floor is satisfactory when $L_{s l} / B_{s l}>1.25$; otherwise it should be divided by $C_{b f}$ to 


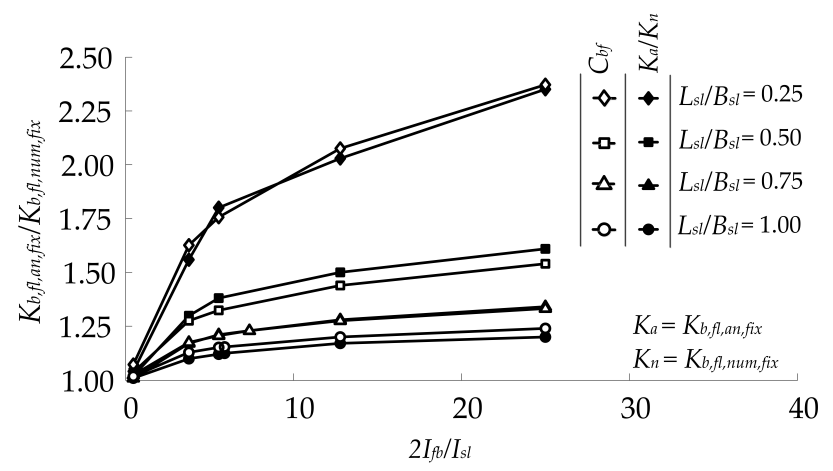

Figure 6: Comparison of $K_{b, f l, a n, f i x} / K_{b, f l, n u m, f i x}$ and $C_{b f}$ for different values of $L_{s l} / B_{s l}$

obtain a good approximation of the numerical bending stiffness of the floor:

$$
K_{b, f l, e q, f i x}=\frac{K_{b, f l, a n, f i x}}{C_{b f}}
$$

where $K_{b, f l, e q, f i x}$ is the equivalent bending stiffness of the fixed support floor (subscript eq denotes an equivalent parameter based on a curve-fitting coefficient $C$ ).

\section{Stage 2: evaluation of floor boundary condition}

In stage 1, the simulations were performed on fixed-ended floors, however this case does not reflect the reality of framed buildings. To evaluate the effect of the real degree of end fixity of the loaded floor, numerical simulations were performed including additional (up to 6) panels in the x-direction. Figure 3c shows an illustrative numerical model of a single storey building with a single bay in the $\mathrm{y}$-direction and multiple bays in the $\mathrm{x}$-direction. The range of dimensions of the structural parts considered are presented in Table 2. It is worth noting that column cross sectional dimensions depended on the cross 
sectional dimensions of the floor and supporting beams (i.e. $h_{c o l}=b_{s b}$ and $\left.b_{c o l}=b_{f b}\right)$.

Table 2: Range of sizes of structural parts considered in stage 2 analyses

\begin{tabular}{|l|c|c|c|c|c|c|}
\hline Parameter & $L_{s l}$ & $B_{s l}$ & $t_{s l}$ & $b_{f b}$ and $b_{s b}$ & $h_{f b}$ and $h_{s b}$ & $L_{c o l}$ \\
\hline Range $(\mathrm{m})$ & 3.5 to 8 & 2.5 to 7 & 0.075 to 0.175 & 0.15 to 0.4 & 0.25 to 0.6 & 1.75 to 4 \\
\hline
\end{tabular}

Six scenarios were analysed; first considering only one x-panel and subsequently adding panels in the $\mathrm{x}$-direction. The numerical simulations were conducted as follows: a fixed boundary was applied to the bottom of all columns except the virtual (displaced) columns (Figure 3c). First, only the loaded panel $\left(x_{0} y_{0}\right.$ in Figure $3 \mathrm{c}$, including the loaded floor, supporting beam and two columns at $x 1$ ) was included in the analysis. A specific uniform displacement was applied to the cross section of the loaded floor and the nodal reaction forces were determined. The floor bending stiffness was then calculated based on Equation 6. One supporting panel (Figure 3c) was then added to the analysis and the same procedure was repeated to determine the floor bending stiffness of the loaded panel. This process was repeated until five supporting panels were added to the analysis. Note that in all simulations, the displacements were only applied to the cross section of the loaded floor.

Adding supporting panels provides an additional degree of end fixity to the loaded floor, which effectively specifies the value of $F_{K}$ in Equation 5 for the loaded panel. The degree of end fixity here means how the supported end of the floor is constrained. The term is related to the connection of the loaded floor to the supporting beam and columns. If the connection does not 




(a)

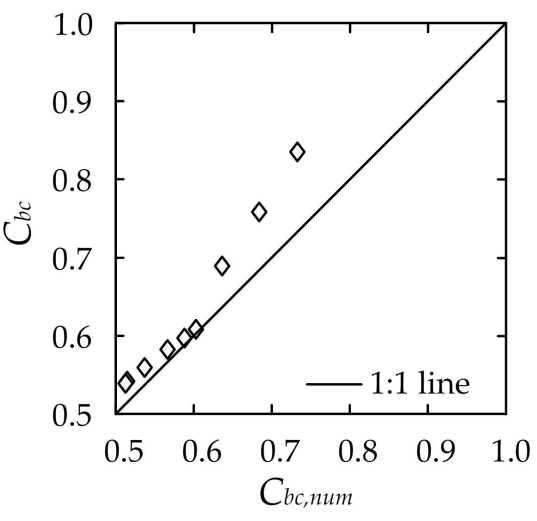

(b)

Figure 7: (a) Effect of supporting floors on the end fixity of the loaded floor, (b) Comparison of proposed $C_{b c}$ values (Equation 9) with numerical results 
porting panels) depends on the stiffness of the supporting beam and columns $\left(x_{1} y_{0}\right.$ and $x_{1} y_{1}$ in Figure $\left.3 c\right)$. The ratio of $b_{s b} / h_{s b}$ is also an influential parameter as it has a significant effect on the rotation of the loaded floor and provides its end fixity. Figure 7a illustrates that the bending stiffness of a single loaded panel is very small compared to the bending stiffness of its fixed-ended scenario (i.e from stage 1).

The stiffness of the supporting beam, two supporting columns $\left(x_{1} y_{0}\right.$ and $x_{1} y_{1}$ in Figure $3 \mathrm{c}$ ) and the floor of the first supporting panel (panel $x_{1} y_{0}$ in Figure 3c) have the most significant effect on the degree of end fixity of the loaded floor. Based on these parameters, the following modification coefficient $C_{b c}$ is proposed to estimate the degree of end fixity of the loaded floor:

$$
C_{b c}=\frac{K_{c, S f l}+K_{c, s b}+2 K_{c, c o l}}{K_{c, L f l}+K_{c, S f l}+K_{c, s b}+2 K_{c, c o l}}<1.0
$$

where $K_{c, S f l}=(E I / L)_{f l}$ is the stiffness of the supporting floor, $K_{c, L f l}=$ $K_{c, S f l}$ is the stiffness of the loaded floor, $K_{c, s b}=G_{b} J_{s b} / L_{s b}$ is the rotational stiffness of the supporting beam (subscript $s b), G_{b}=E_{b} / 2\left(1+\nu_{b}\right)$ is the shear modulus of the beam material, $J_{s b}=\left(b_{s b} h_{s b} / 12\right) \times\left(b_{s b}^{2}+h_{s b}^{2}\right)$ is the polar moment of inertia, $L_{s b}$ is the supporting beam length (equal to the slab width $\left.B_{s l}\right), K_{c, c o l}=(E I)_{c o l} / L_{c o l}$ is the column stiffness, and $L_{c o l}$ is the column height. Note that the $K_{c}$ terms are stiffness parameters used for calculating coefficients, with units of Nm (as opposed to beam/building bending stiffness parameters, $K_{b}$, with units of $\mathrm{N} / \mathrm{m}$ ). The coefficient $C_{b c}$ can be used to evaluate the bending stiffness of the loaded floor in the first storey of a single y-bay building using 


$$
K_{b, f l, e q, 1 s, 1 y}=C_{b c} \times K_{b, f l, e q, f i x}
$$

where $K_{b, f l, e q, f i x}$ is obtained from Equation 8.

Figure $7 \mathrm{~b}$ compares results of $C_{b c}$ using Equation 9 with $C_{b c, \text { num }}=K_{b, f l, n u m, 1 s, 1 y}$ $/ K_{b, f l, n u m, f i x}$, an equivalent coefficient determined from numerical analyses. The results show that the equivalent values using Equation 9 give a satisfactory match to the numerical results.

\section{Stage 3: effect of adding storeys}

Numerical analyses were conducted to evaluate the stiffness effect of adding up to 10 storeys to the single y-bay building from stage 2 , as shown in Figure 3d. The sizes of floors, beams, and columns considered were the same as in stage 2 (Table 2). The area of applied displacements is consistent with stage 2, as indicated in Figure 3d. For a given number of x-bays (up to 10), numerical analyses were conducted sequentially by adding additional storeys. The first storey is used as a reference for which the bending stiffness is compared when additional storeys are added, thereby illustrating the additional bending stiffness each storey contributes.

Columns transfer foundation displacements to upper storeys, but they also convey the stiffness contribution of upper storeys to the foundation. The influence of a storey on the overall structural response is therefore proportional to the relative stiffness of columns compared to the connected floors. The ratio of column stiffness to that of the upper floor can be used as a parameter to quantify this effect. In this way, the column stiffness takes into account the distance between floors. When the global building system is con- 
sidered, the influence of the distance from the foundation to the considered floor is also important. Based on these two factors, a column-floor stiffening effect coefficient $C_{c f}$ is introduced:

$$
C_{c f, i}=\frac{2 K_{c, c o l}}{2 K_{c, c o l}+K_{c, L f l}} \times\left(\frac{L_{c o l, i}}{h_{f l, i}}\right)
$$

where subscript $i$ indicates a measurement for the $i^{\text {th }}$ floor, $L_{c o l, i}$ is column height, and $h_{f l, i}$ is the total height between the $i^{\text {th }}$ floor and the foundation, as shown in Figure 3d.

A coefficient $C_{K u s, i}$ is defined as the ratio of the increased bending stiffness of the superstructure due to the addition of the $i^{\text {th }}$ upper storey (subscript us) to the bending stiffness of the first storey. Figure 8 illustrates how the addition of x-bays and storeys affects the value of $C_{K u s}$. The number of xbays is shown to have an effect on $C_{K u s}$ up to approximately 8 (Figure 8a). Figure $8 \mathrm{~b}$ plots the value of $C_{K u s}$ obtained for each storey within a 7 -storey building with, 3, 6, and 9 x-bays. The data illustrate the decreasing trend of $C_{K u s}$ with storey number as well as the increase of $C_{K u s}$ with number of x-bays.

The numerical analyses indicated that $C_{K u s}$ has a logarithmic relationship with $C_{c f}$, as illustrated in Figure 9 for cases of high, intermediate, and low column stiffness relative to the loaded floor stiffness $\left(2 K_{c, c o l} / K_{c, L f}=0.905\right.$, 0.617 , and 0.207 , respectively) in a 6 storey building; the data can be reasonably well fitted with the following curve:

$$
C_{K u s, i}=\log _{10}\left(C_{c f, i}\right)+\alpha_{K u s} \quad \geq 0.0
$$




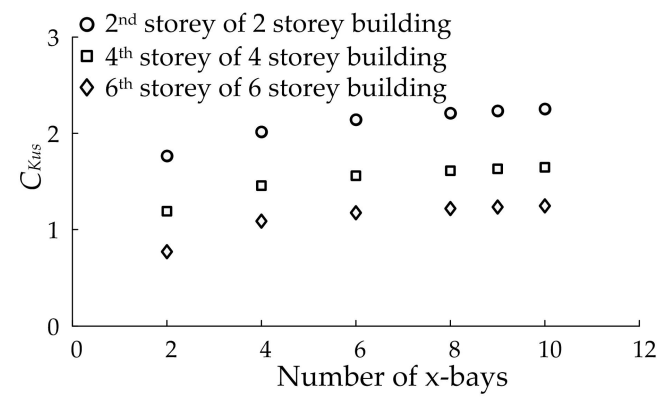

(a)

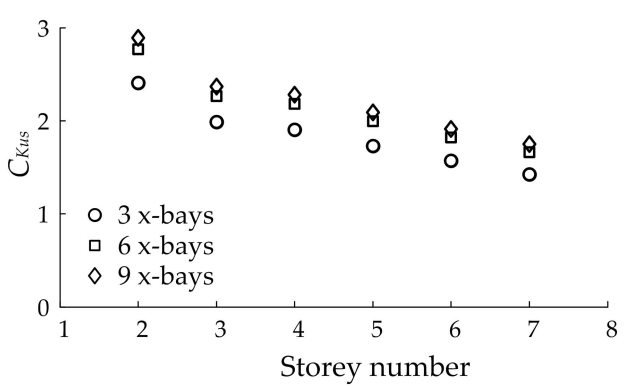

(b)

Figure 8: (a) Effect of x-bays on $C_{K u s}$ of uppermost floor, and (b) change of $C_{K u s}$ with storey number for a 7 -storey building.

where $\alpha_{K u s}$ accounts for the effect of the ratio of building length in the xdirection, $L_{x, b l d g}$, to the storey height, $L_{c o l}$. Note that the effect of distance of each storey from the foundation is included in coefficient $C_{c f}$ (Equation 11). Figure 10 illustrates the relationship between $\alpha_{\text {Kus,num }}$, obtained from the numerical results, and the ratio $L_{x, b l d g} / L_{c o l}$. The numerical data in Figure 10 was fitted using the following expression:

$$
\alpha_{\text {Kus }}=1.9\left(\frac{L_{x, b l d g}}{L_{c o l}}\right)^{0.2}
$$

The stiffness contribution of each storey is obtained by multiplying $C_{K u s, i}$ by its floor bending stiffness, $K_{b, f l, e q, i, 1 y}$ (note that, based on assumption [v] that floor parameters remain constant across all storeys, $K_{b, f l, e q, i, 1 y}=$ $K_{b, f l, e q, 1 s, 1 y}$, which is calculated in stage 2 of the analysis). The bending stiffness of the entire multi-storey (subscript $m s$ ) single y-bay building $\left(K_{b, f l, e q, m s, 1 y}\right)$ is then obtained by summing the individual storey contribu- 


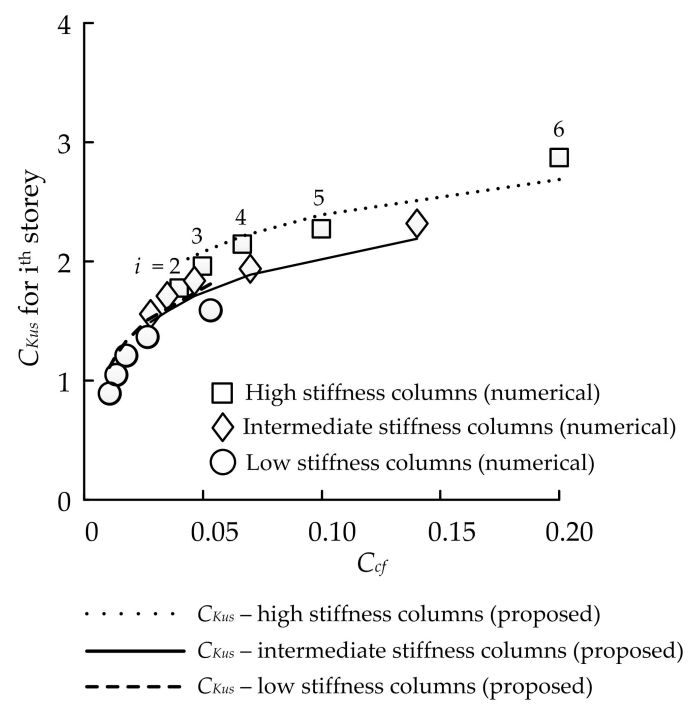

Figure 9: Relationship between $C_{K u s}$ and $C_{c f}$ for a 6 -storey building with varying column stiffness.

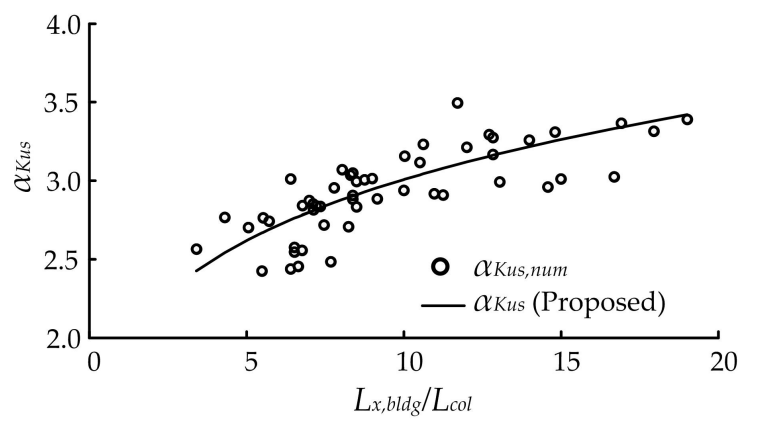

Figure 10: Comparison between $\alpha_{K u s}$ values obtained from curve fitting of numerical results, and proposed values calculated by Equation 13 




Figure 11: Bending stiffness of single y-bay, multi-storey (up to 11 storeys) buildings: proposed method $\left(K_{b, f l, e q, m s, 1 y}\right)$ versus numerical results $\left(K_{b, f l, n u m, m s, 1 y}\right)$

tions:

$$
K_{b, f l, e q, m s, 1 y}=\sum_{i=1}^{m}\left(C_{K u s, i} \times K_{b, f l, e q, i, 1 y}\right)
$$

where $m$ is the total number of storeys. Figure 11 compares the bending stiffness of single y-bay buildings computed using the proposed method (using stages 1 to 3) with their equivalent numerical results. The figure includes 208 data points including buildings of 1 to 11 storeys.

\section{Stage 4: effect of adding y-bays in direction of tunnel}

This section considers the effect of adding bays in the direction of the tunnel (y-direction) on the stiffness of the building. Figure 12a demonstrates the change of $C_{K u s}$ for each storey of a 5-storey building as the number of y-bays is increased from 1 to 3 , based on the numerical analyses. The value of $C_{K u s}$ for the $i^{t h}$ floor was calculated from the numerical results as $\left(K_{b, f l, i}-K_{b, f l,(i-1)}\right) / K_{b, f l, 1}$. Also included in Figure 12a are values obtained 


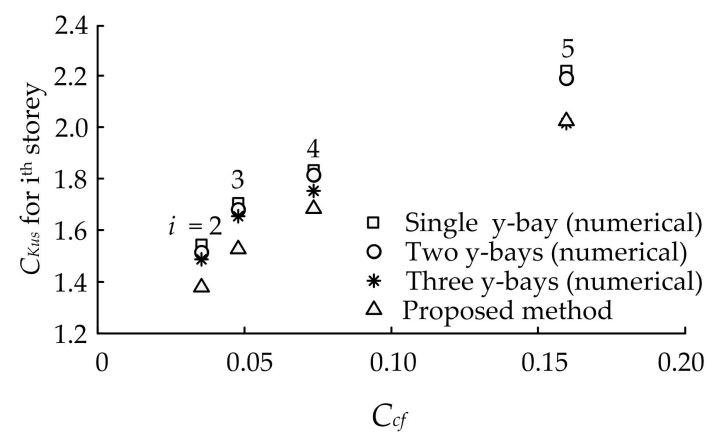

(a)

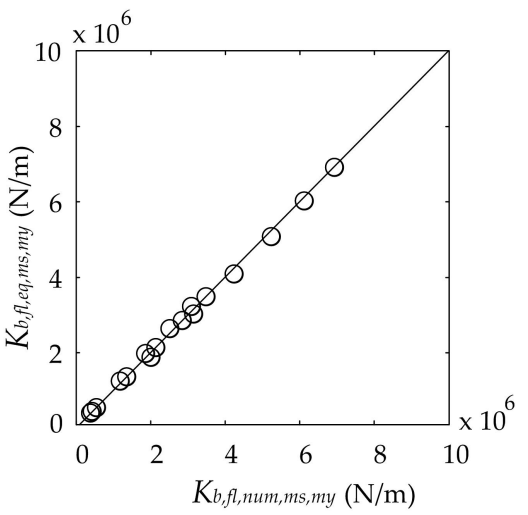

(b)

Figure 12: (a) Comparison between numerical and proposed values of $C_{K u s}$ considering buildings with different numbers of y-bays, (b) comparison of the numerical bending stiffness of multi y-bay buildings with their equivalent calculated values based on stages 1 to 4

using the proposed method (Equation 12) for a single y-bay building.

The numerical results show that the addition of each y-bay increases the bending stiffness of the building superstructure by approximately $60 \%$ of the bending stiffness of a single y-bay building. For this reason, Equation 15 is proposed to estimate the bending stiffness of a multi-storey building with multiple y-bays (subscript $m y), K_{b, f l, e q, m s, m y}$ :

$$
K_{b, f l, e q, m s, m y}=\left(1+0.6\left(n_{y}-1\right)\right) \times K_{b, f l, e q, m s, 1 y}
$$

where $n_{y}$ is the number of y-bays. An example calculation of building stiffness using the proposed method is provided in Appendix A. Figure 12b compares the bending stiffness of multi y-bay buildings obtained from the numerical analyses with those obtained using the proposed method (stages 1 to 4 ). The buildings range from 2 to 3 y-bays, and 1 to 7 storeys. 


\section{Stage 5: considering multiple x-bays affected by ground dis- placements}

The numerical simulations thus far only considered the case where one edge panel of the building was subjected to downward displacements (i.e. affected by tunnelling settlements). When more panels are affected, the bending stiffness of the building will decrease dramatically due to the increased deflected length of the building (bending stiffness is inversely proportional to the cube of affected length, as in Equation 5).

Figure 13 shows a tunnel constructed close to a building. If the building is located entirely inside the displaced soil zone, the bending stiffness of the superstructure will not have a significant contribution to the global building bending stiffness because the whole structure is subjected to rotation. This rotation does not allow the building to provide any resistance against the produced bending deformations. As explained in previous sections, the resistance of the building against bending deformations is achieved when a part of the building is located outside the displaced soil zone, providing a degree of end-fixity.

To consider the effect of the influenced length of the building, numerical simulations were performed to evaluate how bending stiffness of a storey decreases when more panels are affected by ground displacements. It was assumed that the building behaves like a cantilever beam subjected to multiple loads, as shown in Figure 14. Multi-storey buildings with 1 y-bay and $8 \mathrm{x}$ bays were numerically simulated. The number of affected panels considered was 1,2, 3 and 4; the bases of columns in the unaffected zone were fixed. The displacement was modelled by applying forces at the locations of the 




Figure 13: Soil and building zones affected by tunnelling induced ground displacements

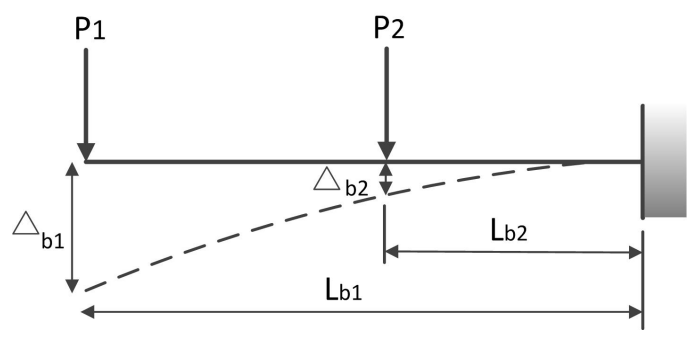

Figure 14: A cantilever beam subjected to multiple loads

affected columns; the applied forces changed linearly from a maximum value above the tunnel centreline to zero at the first column in the unaffected zone.

The analytical bending stiffness of a beam subjected to multiple loads is significantly more complicated than for a single load. A simplified method for approximating bending stiffness of a beam subjected to multiple loads is proposed using the following expression:

$$
K_{b, \text { multi load }}=\frac{P_{1} L_{b 1}+P_{2} L_{b 2}+\ldots+P_{n} L_{b n}}{\Delta_{b 1} L_{b 1}+\Delta_{b 2} L_{b 2}+\ldots+\Delta_{b n} L_{b n}}
$$


where $P$ is a concentrated load, $\Delta_{b}$ is deflection at the location of $P, L_{b}$ is the distance from $P$ to the end of the affected zone (i.e. beginning of the assumed fixity), and subscripts $1,2, \ldots n$ represent the column locations, starting from that nearest to the tunnel. Equation 16 is simply a weighted representation of bending stiffness considering the multiple locations of the loads and measured displacements and is used to obtain the general trend of bending stiffness reduction of a beam subjected to multiple loads in comparison to a beam subjected to a single load. Note that Equation 16 is the same as Equation 6 when the beam is subjected to a single force at its end.

A reduction factor, $C_{K, \text { reduct }}$, is defined as the ratio of the bending stiffness of a building with multiple affected panels to its bending stiffness with one affected panel. This allows the conversion of the building bending stiffness calculated in Stages 1-4 (based on one affected panel) to one which considers the actual number of affected panels (based on an assumed settlement profile).

Figure 15a plots results for a single y-bay, 8 x-bay, 1 storey building when the number of affected panels is increased from one to four and illustrates that there is a dramatic reduction of the building bending stiffness when two or more panels are affected by ground displacements. The results also indicate that $C_{K, \text { reduct }}$ is insensitive to panel size $\left(L_{s l} / B_{s l}\right)$. Figure $15 \mathrm{~b}$ shows results for the same building but with additional storeys added; a slight increase in the value of $C_{K, \text { reduct }}$ is noted for multi-storey buildings. Based on these numerical results, $C_{K, \text { reduct }}$ can be expressed as:

$$
C_{K, \text { reduct }}=F_{s t} \times \frac{L_{x b a y}^{3}}{L_{\text {inf }}^{3}}
$$




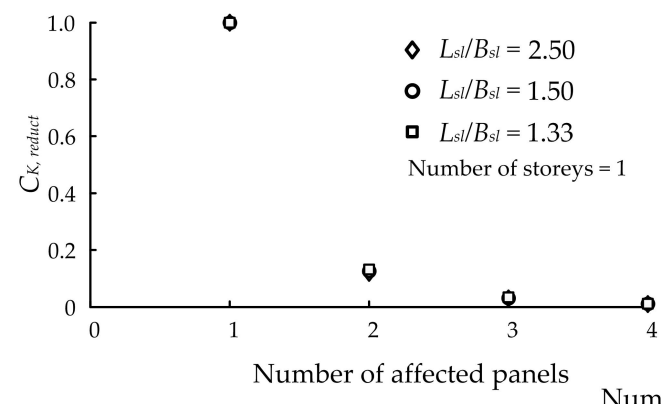

(a)

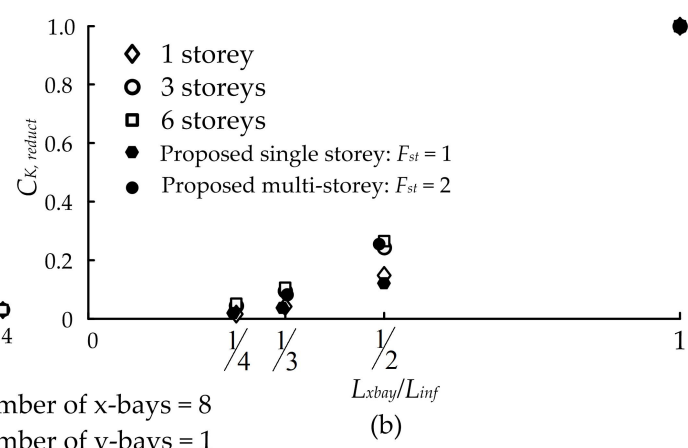

(b)

Figure 15: (a) Reduction of building bending stiffness with the number of panels located in the displaced zone

where $L_{x b a y}$ is the length of one bay in the x-direction (Figure 13), $L_{\text {inf }}$ is the length of the building located inside the affected zone (Figure 13), and $F_{s t}=1$ and 2 for one-storey and multi-storey buildings, respectively. The value of $L_{\text {inf }}$ can be calculated as $L_{i n f}=L_{d s}-L_{T B}$, where $L_{d s}$ is the half length of the displaced zone and $L_{T B}$ is the horizontal offset of the building edge to the tunnel centreline (see Figure 13). For practical purposes, $L_{i n f}$ should correspond to the location of a building column.

The final value of the building bending stiffness, $K_{b, e q, b l d g}$, can be calculated using:

$$
K_{b, e q, b l d g}=C_{K, r e d u c t} \times K_{b, f l, e q, m s, m y}
$$

where $C_{K, \text { reduct }}=1$ if tunnelling settlements only affect the first x-bay or calculated using Equation 17 otherwise.

\section{Comparison of results with other methods}

For comparison against the 2D analysis methods of Lambe (1973) and Goh and Mair (2014), a 2D based calculation of EI from the method pro- 
posed in this paper is used. It is worth noting that the propsed method is based on 3D buildings where bending stiffness of the whole building is calculated rather than the cross sectional flexural rigidity. To show an approximate comparison with the available $2 \mathrm{D}$ methods, coefficient $C_{K u s}$ is used to consider the contribution of $E I$ of each storey to the global $E I_{b l d g}$. The procedure is as follows. The value of $E I_{f l}$ was calculated for the cross section of each floor. It should be noted that $I_{f l}$ was calculated using the parallel axis theorem, as explained in Section 3. The values of $C_{K u s}$ based on the proposed method (stages 1 to 3) were then calculated for each storey (above the first storey) in the building. Finally, the increase of $E I_{f l}$ of the first storey due to the effect of $E I_{f l}$ of the upper storeys was computed to obtain the global $E I_{b l d g}$.

For the approach of Lambe (1973), EI of all floor slabs was added together to achieve EI of the whole building. For Goh and Mair (2014), Equation 3 was used to compute the column stiffening factor $\left(C_{c o l}\right)$ assuming $L_{\text {sag,hog }}^{2} / L_{\text {bay }}^{2}=1$, indicating that only one bay of the frame was affected by ground displacements. With regard to the 3D buildings, the proposed method was compared against the bending stiffness obtained using the approaches of Potts and Addenbrooke (1997) and Franzius et al. (2006) as well as results obtained from the numerical analyses conducted as part of this project (details of the numerical models were presented in stages 1 to 3 ). For both 2D and 3D cases, the comparison was made for a multi-storey (1 to 11) single y-bay building with the parameters given in Table 3 .

Figure 16 shows that the approach used by Lambe (1973) results in the lowest values of $E I_{\text {bldg }}$ because it disregards the effect of the interaction be- 


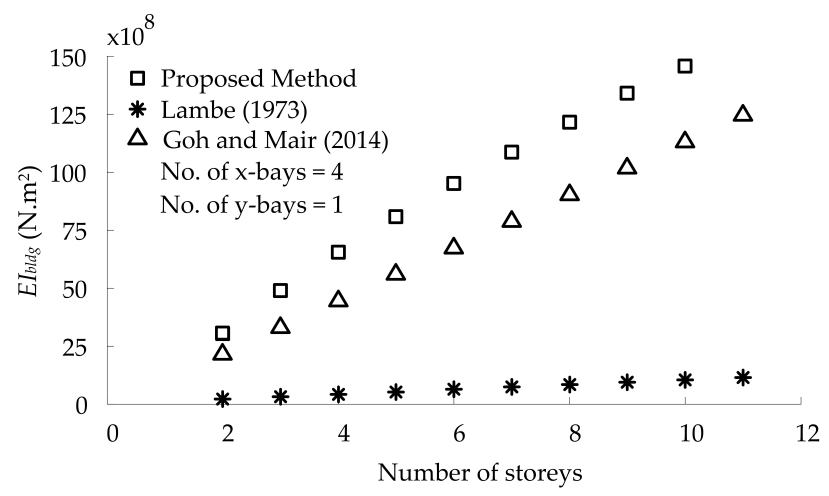

Figure 16: Comparison of $E I_{b l d g}$ between the proposed method and approaches suggested by Lambe (1973) and Goh and Mair (2014)

tween slabs through their connecting links. In the Lambe (1973) method, each slab in the building system is subjected to bending deformations independently, hence the moment of inertia of the building is a straightforward addition of the moment of inertia of each slab and does not consider the effect of the distance between the slabs and the axis about which bending of the building occurs.

Table 3: Sizes of structural parts (1 to 11 storey building) considered in $2 \mathrm{D}$ and $3 \mathrm{D}$ comparative analyses

\begin{tabular}{|l|c|c|c|c|c|c|}
\hline Parameter & $L_{s l}$ & $B_{s l}$ & $t_{s l}$ & $b_{f b}$ and $b_{s b}$ & $h_{f b}$ and $h_{s b}$ & $L_{c o l}$ \\
\hline Dimension $(\mathrm{m})$ & 8.00 & 7.00 & 0.175 & 0.40 & 0.60 & 4.00 \\
\hline
\end{tabular}

The trend of the $E I_{b l d g}$ curves of the proposed method and the method of Goh and Mair (2014) are similar but $E I_{b l d g}$ values of the proposed method are greater by approximately $27 \%$. Values of $E I_{b l d g}$ and their trends will change for different frame geometries. For this reason, it is more logical to plot the column stiffening factor $\left(C_{c o l}\right)$ and $C_{K u s}$ to indicate their difference 


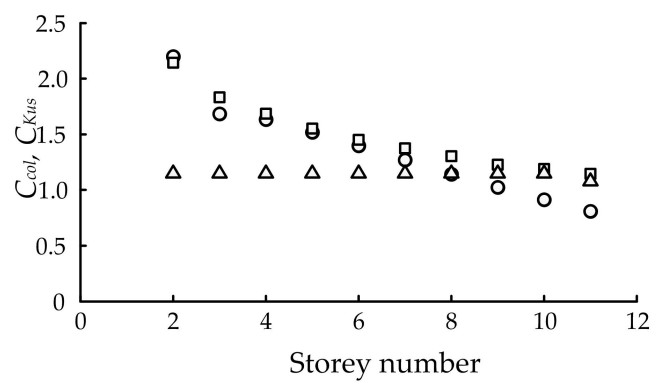

(a)
- Numerical Prediction

口 Proposed Method

$\Delta$ Goh and Mair (2014)

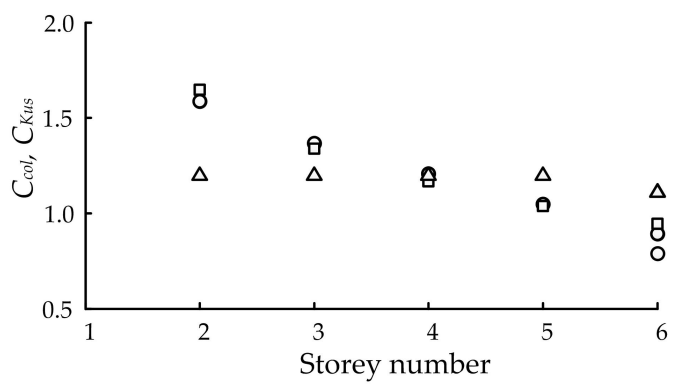

No. of $x$-bays $=4$ No. of $y$-bays $=1$ (b)

Figure 17: Comparison of $C_{c o l}$ and $C_{K u s}$ between the proposed method, the approach suggested by Goh and Mair (2014) and numerically predicted values for (a) an 11 storey, and (b) a 6 storey building.

in estimating the value of $E I_{b l d g}$. Figure 17 displays $C_{c o l}$ of Goh and Mair (2014) and $C_{K u s}$ of the proposed method with the numerically predicted coefficients. The stiffening factor proposed by Goh and Mair (2014) is constant and, similar to the approach of Lambe (1973), disregards the effect of the distance between the desired floor and the axis about which the building bends (i.e. the foundation level). For an 11 storey building, this leads to an underestimation of the contribution of $E I$ of storeys close to the foundation to the global building flexural rigidity $\left(E I_{b l d g}\right)$, whereas it gives an overestimation of the contribution of $E I$ for higher storeys. Figure 17a shows that stiffening factors calculated based on the Goh and Mair (2014) approach were underestimated for storeys 1 to 7 while they were overestimated for storeys 9 to 11 .

For a 6-storey building with less stiff columns $\left(K_{c, c o l}=0.29 \times 10^{7} \mathrm{Nm}\right.$ and $K_{c, \text { beam }}=2.25 \times 10^{7} \mathrm{Nm}$ ), the Goh and Mair (2014) method gives a similar value of building $E I$ to that of the numerical analysis because the column 
stiffening factors in the Goh and Mair (2014) method reasonably reflect an average value of the numerically derived values, as illustreated in Figure 17b. If the building was more than 6 storeys, the Goh and Mair (2014) method would overestimate the building $E I_{\text {bldg }}$ due to the fact that it disregards the reduction of the stiffening factor for the upper storeys.

In the analyses presented above, it was assumed that the affected length of the buildings was only one bay. In case of having more than one bay affected by tunnelling, the magnitude of $L_{\text {sag,hog }}^{2} / L_{b a y}^{2}$, and therefore $E I_{b l d g}$, in the method of Goh and Mair (2014) increases significantly. However, the value of bending stiffness calculated using the proposed method, and that obtained from the numerical analysis, reduces considerably. Therefore, the difference between the values of $E I_{b l d g}$ obtained using the method of Goh and Mair (2014) and that proposed here increases as more bays are influenced by tunnelling.

A comparison of bending stiffness for a 3D building using the numerical prediction, the method proposed in this paper, and the methods of Potts and Addenbrooke (1997) and Franzius et al. (2006) is presented in Figure 18a for buildings of $2,4,6,8$ and 10 storeys. The bending stiffness values of the two latter methods were too large to be plotted on a linear axis with the two former methods. For this reason, the y-axis of Figure 18a is logarithmic. The building bending stiffness was calculated as $(E I)_{b l d g} /\left(L_{b l d g} / 2\right)^{4}$ in the Potts and Addenbrooke (1997) approach, and as $(E I)_{b l d g} /\left(B_{b l d g} L_{b l d g}^{2}\right)$ in the Franzius et al. (2006) method, where $L_{b l d g}=34 \mathrm{~m}$.

It should be noted that the stiffness units of the Potts and Addenbrooke (1997) method is $\mathrm{N} / \mathrm{m}^{2}$ which is different to the stiffness units of the other 


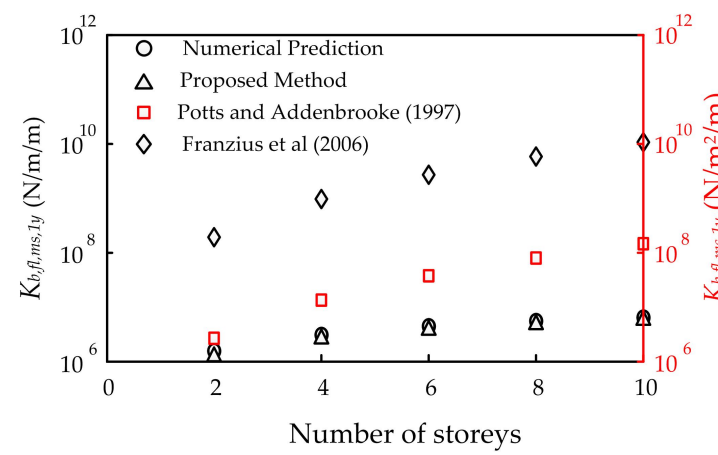

(a)

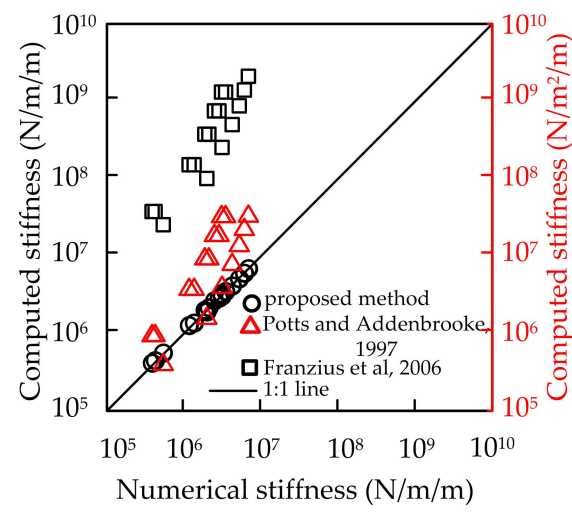

(b)

Figure 18: (a) Comparison of a $3 D$ building bending stiffness using different methods, (b) comparing computed building bending stiffness using different methods with the numerically achieved bending stiffness for buildings with y-bays ranging from 1 to 3

methods. The absolute values can therefore not be directly compared, however the trend of relative increase of stiffness with number of storeys between the methods can be ascertained from the plotted data. The moment of inertia of the global building in the methods proposed by Potts and Addenbrooke (1997) and Franzius et al. (2006) were calculated using the parallel axis theorem, which results in large overestimations of the real building bending stiffness when the number of storeys is increased. In addition, the boundary condition and the length of the building subjected to ground deformations due to tunnelling are not taken into consideration in these methods. The bending stiffness for a relatively long building with a small portion affected by ground deformations will be underestimated while the stiffness of a short building located entirely within the affected zone will be overestimated. This does not give a good representation of reality since building bending stiffness should decrease with the increase of its deformed (affected) length, and should 
increase with the increase of the degree of its end fixity due to a greater constriction of the building against rotation. Figure 18b compares the bending stiffness of a range of multiple y-bay buildings calculated with the proposed method of this work (based on stages 1 to 4 ) with results obtained using the approaches of Potts and Addenbrooke (1997) and Franzius et al. (2006). Results show good agreement between the numerical outcomes and those of the proposed method and again illustrate the observations noted above regarding the overestimation of buildings stiffness using alternative methods.

\section{Summary}

The paper proposed a computationally efficient method to obtain realistic estimates of the bending stiffness of concrete framed buildings affected by tunnelling displacements which depends on the actual parameters of the structural components of the building. Various assumptions and simplifications were made within the methodology, leading to limitations of its applicability. The structural components of the building were assumed to be linear elastic; in reality cracking will occur and non-linear behaviour (a reduction in structural stiffness) can be expected (Son and Cording, 2010; Giardina et al., 2013; Son, 2015). The effect of walls, facades, and partitions within the building was also not considered in the analyses in this paper. This may have an effect on the bending behaviour of the building, however the standard methodology applied in structural design of framed buildings is to omit the effect of walls and partitions (Mirhabibi and Soroush, 2013). 


\section{Conclusions}

This paper presented a method for the evaluation of the response of framed buildings located above newly constructed tunnels. The method is based on an analogy of building behaviour to that of a cantilever beam. A set of empirical-type equations was developed based on evaluations of the stiffness of 3D framed buildings obtained using rigorous finite element analyses.

The analytical expression of a cantilever beam was first adjusted to quantify the bending stiffness of a fixed ended floor panel affected by tunnelling settlements. This expression was then further developed to account for the number of building bays perpendicular to the tunnel (affecting the end-fixity condition), the number of building storeys, and the number of building bays in the direction of the tunnel axis (all assuming only one building bay perpendicular to the tunnel was affected). Finally, a method to account for scenarios where multiple building bays are affected was proposed.

Results demonstrated that the foundation of the building plays a major role in determining its effective stiffness; the contribution of upper storeys was shown to decrease with storey number. The factors influencing the stiffness contribution of each storey to the global building bending stiffness was demonstrated; the ratio of column to floor stiffness was shown to be proportional to the degree of stiffness contribution. Furthermore, the ratio of the length to height of the building was also shown to be proportional to the degree of stiffness contribution.

Results of the proposed method as well as available 2D and 3D approaches for estimating building bending stiffness were compared against the outcomes 
545 of the numerical analyses. The proposed method agrees well with the numer546 ical analyses and captures important trends of the change of building stiffness 547 with number of storeys and building fixity condition that other methods do 548 not. The method offers the advantage of being very computationally efficient 549 compared to numerical analysis, yet achieves a good level of accuracy for the 550 wide range of framed building characteristics considered. 


\section{Appendix A. Practical Example}

This appendix presents an example calculation in order to demonstrate how the proposed method may be used to estimate bending stiffness of a building affected by tunnelling.

Consider a three y-bay, four x-bay, three-storey building made of concrete with an elastic modulus of $30 \mathrm{GPa}$ and Poison's ratio of 0.15 . Column dimensions are $0.3 \times 0.3 \times 3 \mathrm{~m}\left(h_{c o l}, b_{c o l}\right.$, and $L_{c o l}$, respectively), supporting beam dimensions are $0.3 \times 0.5 \mathrm{~m}\left(b_{s b}\right.$ and $\left.h_{s b}\right)$, floor beam dimensions are $0.3 \times 0.5 \mathrm{~m}$ $\left(b_{f b}\right.$ and $\left.h_{f b}\right)$, and slab dimensions are $5 \times 6 \times 0.15 \mathrm{~m}\left(B_{s l}, L_{s l}\left(=L_{f l}\right)\right.$, and $\left.t_{s l}\right)$. Three bays in the $\mathrm{x}$-directions are affected by tunnelling.

1. Determine the centroid of the floor cross section

$\bar{y}_{f l}=\frac{2 \times(0.3 \times 0.5 \times 0.5 / 2)+5 \times 0.15 \times(0.5-0.15 / 2)}{2 \times 0.3 \times 0.5+5 \times 0.15}=0.375 \mathrm{~m}$

2. Determine the floor cross sectional moment of inertia and flexural rigidity

$$
\begin{array}{r}
I_{f l}=\sum\left\{2 \times I_{b}+2 \times A_{b} \cdot\left(\bar{y}_{f l}-\bar{y}_{b}\right)^{2}+I_{s l}+A_{s l} \cdot\left(\bar{y}_{f l}-\bar{y}_{s l}\right)^{2}\right\} \\
=2 \times 0.00313+2 \times 0.00235+0.00141+0.001875=0.01424 \mathrm{~m}^{4} \\
E I_{f l}=30 \times 10^{9} \times 0.01424=42.72 \times 10^{7} \mathrm{Nm}^{2}
\end{array}
$$

3. Calculate the analytical bending stiffness of the floor from Equation 5 using $E I_{f l}$ and $F_{K}=3$ for a cantilever.

$K_{b, f l, a n, f i x}=\frac{3 E I_{f l}}{L_{f l}^{3}}=\frac{3 \times 42.72 \times 10^{7}}{6^{3}}=0.59 \times 10^{7} \mathrm{~N} / \mathrm{m}$

4. The ratio of $L_{s l} / B_{s l}=1.2$ is smaller than 1.25 , hence the analytical floor 
bending stiffness should be divided by coefficient $C_{b f}$ (Equation 7 ) to obtain $K_{b, f l, e q, f i x}$ (Equation 8).

$$
\begin{array}{r}
C_{b f}=\left(\frac{6 I_{f b}}{I_{s l}}\right)^{\frac{B_{s l}}{20 L_{s l}}}=\left(\frac{6 \times 0.00313}{0.00141}\right)^{\frac{5}{20 \times 6}}=1.114 \\
K_{b, f l, e q, f i x}=\frac{K_{b, f l, a n, f i x}}{C_{b f}}=\frac{0.59 \times 10^{7}}{1.114}=0.53 \times 10^{7} \mathrm{~N} / \mathrm{m}
\end{array}
$$

5. Convert the bending stiffness of the fixed floor $\left(K_{b, f l, e q, f i x}\right)$ to that of the actual floor connected to structural parts $\left(K_{b, f l, e q, 1 s, 1 y}\right.$, Equation 10) using coefficient $C_{b c}$ (Equation 9)

$$
\begin{gathered}
G_{b}=\frac{E_{b}}{2\left(1+\nu_{b}\right)}=\frac{30 \times 10^{9}}{2(1+0.15)}=13.04 \times 10^{9} \mathrm{GPa} \\
K_{c, L f l}=K_{c, S f l}=\frac{E I_{f l}}{L_{f l}}=\frac{42.72 \times 10^{7}}{6}=7.12 \times 10^{7} \mathrm{Nm} \\
J_{s b}=\frac{b_{s b} h_{s b}}{12} \times\left(b_{s b}^{2}+h_{s b}^{2}\right)=\frac{0.3 \times 0.5}{12} \times\left(0.3^{2}+0.5^{2}\right)=0.00425 \mathrm{~m}^{4} \\
K_{c, s b}=\frac{G_{b} J_{s b}}{L_{s b}}=\frac{13.04 \times 10^{9} \times 0.00425}{5}=1.11 \times 10^{7} \mathrm{Nm} \\
K_{c, c o l}=\frac{E I_{c o l}}{L_{c o l}}=\frac{30 \times 10^{9} \times 0.3 \times 0.3^{3}}{12 \times 3}=0.675 \times 10^{7} \mathrm{Nm} \\
=\frac{K_{c, S f l}+K_{c, s b}+2 K_{c, c o l}}{2 \times 7.12 \times 10^{7}+1.11 \times 10^{7}+2 \times 0.675 \times 10^{7}}=0.574 \\
K_{c, L f l}+K_{c, S f l}+K_{c, s b}+2 K_{c, c o l} \\
K_{b, f l, e q, 1 s, 1 y}=C_{b c} \times K_{b, f l, e q, f i x}=0.574 \times 0.53 \times 10^{7} \\
=0.304 \times 10^{7} \mathrm{~N} / \mathrm{m}
\end{gathered}
$$


6. Compute column stiffening factors $\left(C_{c f}\right)$ based on Equation 11

$$
\begin{array}{r}
C_{c f 2}=\frac{2 K_{c, c o l}}{2 K_{c, c o l}+K_{c, L f l}} \times\left(\frac{L_{c o l, 2}}{h_{f l, 2}}\right)=\frac{2 \times 0.675 \times 10^{7}}{2 \times 0.675 \times 10^{7}+7.12 \times 10^{7}} \times \frac{3}{3.5}=0.137 \\
C_{c f 3}=0.0683
\end{array}
$$

7. Calculate $\alpha_{K u s}$ from Equation 13, and then evaluate $C_{K u s, i}$ for each upper storey using Equation 12.

$$
\begin{array}{r}
\frac{L_{x, b l d g}}{L_{c o l}}=\frac{4 \times 6+5 * 0.3}{3}=8.5 \\
\alpha_{K u s}=1.9\left(\frac{L_{x, b l d g}}{L_{c o l}}\right)^{0.2}=1.9 \times 8.5^{0.2}=2.914 \\
C_{K u s, 2}=\log _{10}\left(C_{c f, 2}\right)+\alpha_{K u s}=\log _{10}(0.137)+2.914=2.05 \\
C_{K u s, 3}=1.748
\end{array}
$$$$
\text { 8. The total bending stiffness of the single y-bay building superstructure with }
$$
one deflected panel $\left(K_{b, f l, e q, m s, 1 y}\right)$ can now be calculated using Equation 14. The calculation is summarised in Table A.4.

Table A.4: Calculation of the total Building Stiffness

\begin{tabular}{|l|c|c|c|}
\hline Floors & $K_{b, f l, e q, i, 1 y}=K_{b, f l, e q, 1 s, 1 y}(\mathrm{~N} / \mathrm{m})$ & $C_{K u s, i}$ & $\begin{array}{l}\text { Contribution } \\
\text { each storey } \quad \begin{array}{r}\text { of } \\
(\mathrm{N}) \\
\left(C_{K u s, i} \times K_{b, f l, e q, i, 1 y}\right)\end{array}\end{array}$ \\
\hline $1^{\text {st }}$ & $0.304 \times 10^{7}$ & - & $0.304 \times 10^{7}$ \\
\hline $2^{\text {nd }}$ & $0.304 \times 10^{7}$ & 2.050 & $0.62 \times 10^{7}$ \\
\hline $3^{\text {rd }}$ & $0.304 \times 10^{7}$ & 1.748 & $0.53 \times 10^{7}$ \\
\hline Total & & & $1.454 \times 10^{7} \mathrm{~N} / \mathrm{m}$ \\
\hline
\end{tabular}

9. There are three bays in the y-direction. The effects of the two extra bays 
can be added using Equation 15.

$$
\begin{array}{r}
K_{b, f l, e q, m s, m y}=\left(1+0.6\left(n_{y}-1\right)\right) \times K_{b, f l, e q, m s, 1 y}=(1+0.6 \times(3-1)) \times 1.454 \times 10^{7} \\
=3.20 \times 10^{7} \mathrm{~N} / \mathrm{m}
\end{array}
$$

${ }_{564}$ The numerical stiffness result of the analysed building is $3.17 \times 10^{7} \mathrm{~N} / \mathrm{m}$. ${ }_{565}$ The proposed result is $3.20 \times 10^{7} \mathrm{~N} / \mathrm{m}$. This leads to an overestimation of 566 about $1 \%$.

567 10. Calculate coefficient $C_{K, \text { reduct }}$ from Equation 17, and then compute the 568 final bending stiffness of the building using Equation 18.

${ }_{569} L_{x b a y}=6.3 \mathrm{~m}$ (centre to centre)

${ }_{570} L_{\text {inf }}=3 \times 6.3=18.9 \mathrm{~m}$

${ }_{571} C_{K, \text { reduct }}=F_{\text {st }} \times \frac{L_{\text {xbay }}^{3}}{L_{\text {inf }}^{3}}=2 \times \frac{6.3^{3}}{18.9^{3}}=0.074$

${ }_{572} K_{b, e q, b l d g}=C_{K, \text { reduct }} \times K_{b, f l, e q, m s, m y}=0.074 \times 3.20 \times 10^{7}=0.237 \times 10^{7} \mathrm{~N} / \mathrm{m}$

573 It is worth noting that the numerical analysis of the building yielded a value 574 of $C_{K, \text { reduct }}=0.063$. 
Attewell, P. B., Yeates, J., Selby, A. R., 1986. Soil movements induced by tunnelling and their effects on pipelines and structures. Blackie and Son Ltd, UK.

Boscardin, M. D., Cording, E. J., 1989. Building Response to ExcavationInduced Settlement. Journal of Geotechnical Engineering 115 (1), 1-21.

Dimmock, P. S., Mair, R. J., 2008. Effect of building stiffness on tunnellinginduced ground movement. Tunnelling and Underground Space Technology $23(4), 438-450$.

Fargnoli, V., Gragnano, C., Boldini, D., Amorosi, A., 2015. 3D numerical modelling of soil-structure interaction during EPB tunnelling. Géotechnique 65 (1), 23-37.

Farrell, R., Mair, R., 2012. Centrifuge modelling of the response of buildings to tunnelling. In: Proc. of the International Symposium on Geotechnical Aspects of Underground Construction in Soft Ground. pp. 343-351.

Farrell, R., Mair, R., Sciotti, A., Pigorini, A., 2014. Building response to tunnelling. Soils and Foundations 54 (3), 269-279.

Franza, A., Marshall, A. M., Haji, T., Abdelatif, A. O., Carbonari, S., Morici, M., 2017. A simplified elastic analysis of tunnel-piled structure interaction. Tunnelling and Underground Space Technology 61, 104-121.

Franzius, J. N., Potts, D. M., Addenbrooke, T. I., Burland, J. B., 2004. The influence of building weight on tunnelling-induced ground and building deformation. Soils and Foundations 45 (4), 168-169. 
Franzius, J. N., Potts, D. M., Burland, J. B., 2006. The response of surface structures to tunnel construction. Proceedings of the ICE-Geotechnical Engineering 159 (1), 3-17.

Giardina, G., DeJong, M. J., Mair, R. J., 2015. Interaction between surface structures and tunnelling in sand: Centrifuge and computational modelling. Tunnelling and Underground Space Technology 50, 465-478.

Giardina, G., Marini, A., Hendriks, M. A., Rots, J. G., Rizzardini, F., Giuriani, E., 2012. Experimental analysis of a masonry façade subject to tunnelling-induced settlement. Engineering Structures 45, 421-434.

Giardina, G., Van de Graaf, A. V., Hendriks, M. A., Rots, J. G., Marini, A., 2013. Numerical analysis of a masonry façade subject to tunnelling-induced settlements. Engineering structures 54, 234-247.

Goh, K. H., Mair, R. J., 2014. Response of framed buildings to excavationinduced movements. Soils and Foundations 54 (3), 250-268.

Lambe, T., 1973. Predictions in soil engineering. Geotechnique 23 (2), 151202 .

Liu, G., Houlsby, G. T., Augarde, C. E., 2001. 2-dimensional analysis. The Structural Engineer 79 (1), 19-25.

Mair, R. J., 2013. Tunnelling and deep excavations: Ground movements and their effects. In: Anagnostopoulos, A. (Ed.), Proceedings of the 15th European Conference on Soil Mechanics and Geotechnical Engineering Geotechnics of Hard Soils âĂŞ Weak Rocks (Part 4). Vol. l. IOS Press. 
Mair, R. J., Taylor, R. N., 1997. Bored Tunnelling in the urban environment. In: Proceed. 14th International Conference on Soil Mechanics and Foundation Engineering. Vol. 4. Balkema, Hamburg, pp. 2353-2385.

Maleki, M., Sereshteh, H., Mousivand, M., Bayat, M., jul 2011. An equivalent beam model for the analysis of tunnel-building interaction. Tunnelling and Underground Space Technology 26 (4), 524-533.

McCormac, J. C., Brown, R. H., 2014. Design of reinforced concrete, 9th Edition. John Wiley \& Sons.

Meyerhof, G., 1953. Some recent foundation research and its application to design. The Structural Engineer 31 (6), 151-167.

Mirhabibi, A., Soroush, A., 2013. Effects of building three-dimensional modeling type on twin tunneling-induced ground settlement. Tunnelling and underground space technology 38, 224-234.

Mroueh, H., Shahrour, I., 2003. A full 3-d finite element analysis of tunnelingadjacent structures interaction. Computers and Geotechnics 30 (3), 245253.

Pickhaver, J. A., Burd, H. J., Houlsby, G. T., oct 2010. An equivalent beam method to model masonry buildings in 3D finite element analysis. Computers \& Structures 88 (19-20), 1049-1063.

Potts, D., Addenbrooke, T., 1997. A structure's influence on tunnellinginduced ground movements. Proceedings of the ICE-Geotechnical Engineering 125 (2), 109-125. 
Rankin, W. J., jan 1988. Ground movements resulting from urban tunnelling: predictions and effects. Geological Society, London, Engineering Geology Special Publications 5 (1), 79-92.

SIMULIA, A., 2012. 6.12. ABAQUS Analysis User's Manual.

Son, M., 2015. Response analysis of nearby structures to tunneling-induced ground movements in sandy soils. Tunnelling and Underground Space Technology 48, 156-169.

Son, M., Cording, E. J., 2010. Responses of buildings with different structural types to excavation-induced ground settlements. Journal of Geotechnical and Geoenvironmental Engineering 137 (4), 323-333.

Wight, J. K., MacGregor, J. G., 2009. Reinforced concrete mechanics and design, 5th Edition. Pearson Education International. 